\title{
Public Policy, Technology Adoption, And Aggregate Energy Efficiency
}

\author{
Winston Harrington, Raymond J. Kopp, Richard D. Morgenstern, \\ William A. Pizer, and Jhih-Shyang Shih
}

\begin{abstract}
This research examines the factors that influence the adoption of new energy-saving technologies among U.S. manufacturing plants and explores their potential impact on aggregate energy efficiency. We conduct this analysis using two models: a conventional diffusion model and a stand-alone model of new technology adoption we develop in this paper. The latter model allows us to compute effects on aggregate efficiency based solely on adoption data.

Our estimates of diffusion speed find a remarkable consistency across technologies and industries. We estimate that half the population of users adopts a new technology in roughly seven years, regardless of industry or technology. Based on a $95 \%$ confidence interval, we estimate that at ten percent rise in energy prices would, at most, decrease the average adoption time by about one year. The obvious problem with this model is that while it explains how the diffusion of individual technologies may be sped up, it does not address the process of developing these new technologies. In a model focused on individual technologies, this process dominates long-run behavior.

Focusing instead on adoption of any technology rather than specific ones, we identify two statistically significant predictors of adoption: profitability and energy prices. Based on a $95 \%$ confidence interval, these variables at most raise the rate of adoption by $3 \%$ and $10 \%$, respectively, when each variable is increased by $10 \%$. In our adoption model, these increases directly translate into changes in the growth rate of energy efficiency. With an aggregate growth rate of roughly $1 \%$, this would indicate an increase to at most $1.1 \%$. At this rate, energy use will have fallen by $43 \%$ instead of $39 \%$ after fifty years - a relatively small gain for fifty years of higher energy prices.
\end{abstract}

From these results we draw two important policy conclusions. Since we find that profitability has a significant effect on adoption, it will be important to consider the impact of public policy on firm revenue. For example, policies that immediately raise prices without allowing firms to anticipate those changes may lead to declining adoption rates if their financial health is adversely affected. Second and more significantly, these results put a damper on the idea that technology can substantially reduce the trade-off between economic costs and environmental protection. Since energy efficiency improvements currently progress at only $1 \%$ per year, even a large increase in this growth rate will take many years to translate into significant reductions in aggregate efficiency. The only possibility for significant technology effects will be if public policy can encourage the development of large, non-incremental technologies-unlike the small, incremental technologies considered in this paper.

Keywords: JEL Classification Numbers:

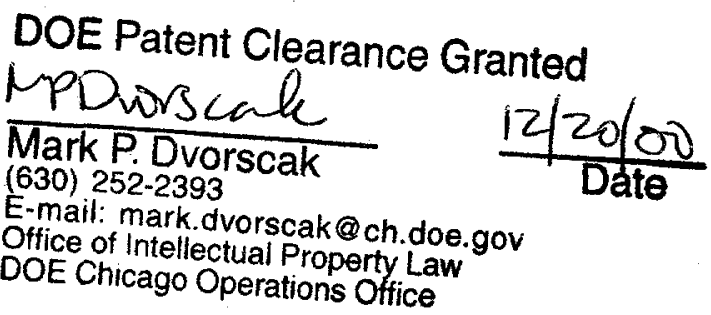




\section{DISCLAIMER}

This report was prepared as an account of work sponsored by an agency of the United States Government. Neither the United States Government nor any agency thereof, nor any of their employees, make any warranty, express or implied, or assumes any legal liability or responsibility for the accuracy, completeness, or usefulness of any information, apparatus, product, or process disclosed, or represents that its use would not infringe privately owned rights. Reference herein to any specific commercial product, process, or service by trade name, trademark, manufacturer, or otherwise does not necessarily constitute or imply its endorsement, recommendation, or favoring by the United States Government or any agency thereof. The views and opinions of authors expressed herein do not necessarily state or reflect those of the United States Government or any agency thereof. 


\section{DISCLAIMER}

Portions of this document may be illegible in electronic image products. Images are produced from the best available original document. 


\section{Table of Contents}

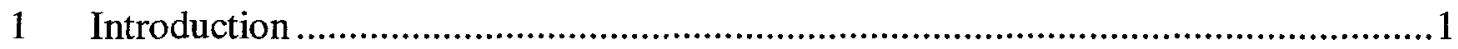

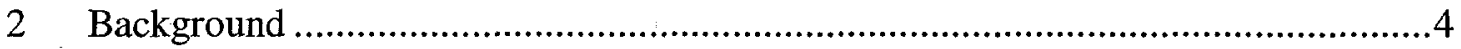

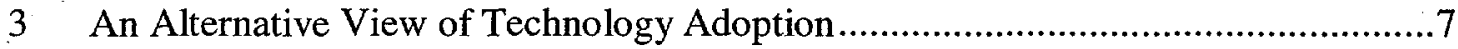

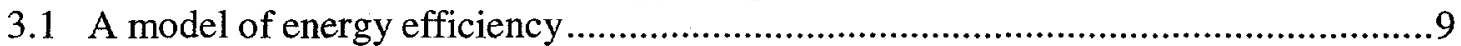

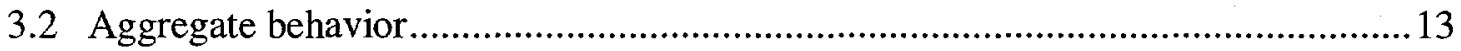

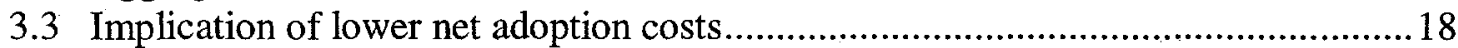

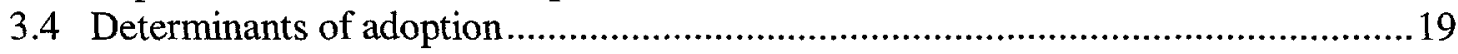

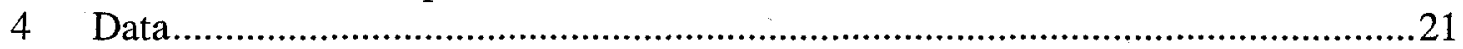

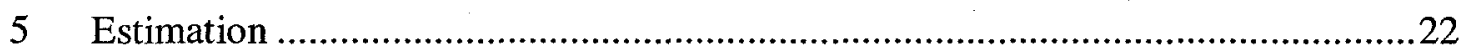

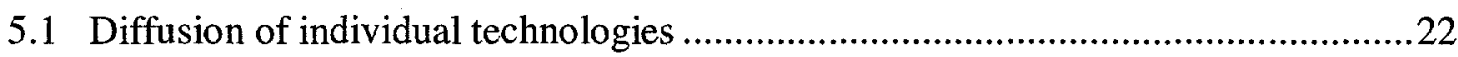

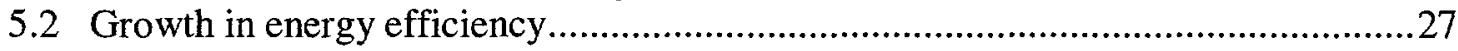

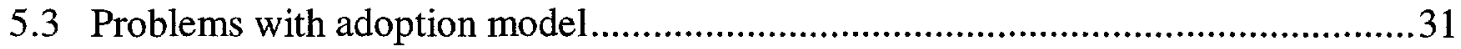

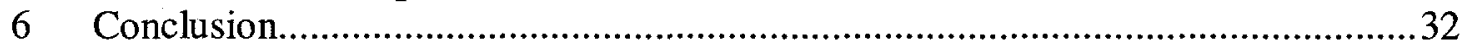

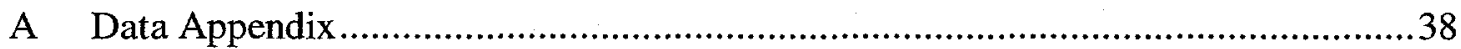

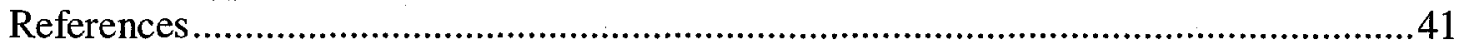

\section{Tables}

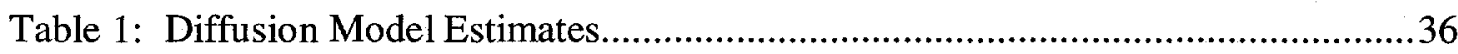

Table 2: Adoption Model Estimates.......................................................................37

Table 3: Descriptive Statistics for the variables used in the estimation ...........................39

\section{Figures}

Figure 1: Steady-state Distribution of Efficiency for Various Parameter Combinations. 17 


\title{
Public Policy, Technology Adoption, And Aggregate Energy Efficiency
}

\author{
Winston Harrington, Raymond J. Kopp, Richard D. Morgenstern, \\ William A. Pizer, and Jhih-Shyang Shih ${ }^{*}$
}

\section{Introduction}

With current technologies, emission of pollutants like greenhouse gases poses a difficult choice between potentially irreversible environmental damage and the burdens associated with potentially high cost mitigation policies. Yet, changes in technology could significantly alter these tradeoffs. It is argued that public policies affecting the development and spread of new technologies may, over the long term, be one of the most important tools for environmental protection.

But how can public policy encourage these activities? In the past, technology mandates have been used to deal with narrow environmental concerns within particular industries. However, the breadth of the GHG problem-over gases, industries, and time-defies such an approach. No one knows which technologies should be used in which industries, especially looking decades into the future. Instead, public policy must create incentives for individual plants to discover and adopt emission-reducing technologies by their own choosing.

\footnotetext{
* The authors are, respectively, Senior Fellow, Senior Fellow, Visiting Scholar, Fellow and Fellow, Quality of the Environment Division, Resources for the Future (Morgenstern is also Associate Assistant Administrator for Policy, on leave, U.S. Environmental Protection Agency). The authors gratefully acknowledge financial support from the U.S. Department of Energy (Office of Energy Research, Integrated Assessment of Global Climate Change Research Program), and the U.S. Environmental Protection Agency (Office of Policy, Office of Economy and the Environment). Phillip Haberkern provided excellent research assistance. The research in this paper was conducted at the Center for Economic Studies, U.S. Bureau of the Census. Mary L. Streitwieser, Gordon M. Phillips and Arnold P. Reznek, have provided considerable assistance for which the authors are greatly appreciative. Research results are those of the authors and do not necessarily indicate concurrence by the Bureau of the Census or the Center for Economic Studies.
} 
In order to guide the design of incentive-based policies, this research examines some of the factors that influence the adoption of new energy-saving technologies among U.S. manufacturing plants and explores their potential impact on aggregate energy efficiency. Using a unique data set linking plant-level data from the Census Department's Longitudinal Research Database, technology-use data from the Manufacturing Energy Consumption Survey and parent-firm financial data from Quarterly Financial Reports we explore the adoption of four technologies in four, 4-digit SIC code industries. We conduct this analysis using two models: a conventional diffusion model and a stand-alone model of new technology adoption we develop in this paper. Unlike the diffusion model which requires a separate model of innovation to draw conclusions about long-run energy efficiency, our stand-alone model presumes that incremental technology options always exist and that adoption decisions alone govern long-run energy efficiency. This allows us to compute effects on aggregate efficiency based solely on adoption data.

In our diffusion model estimation, we find a remarkable consistency across technologies in the speed of diffusion. We estimate that half the population of users adopts each of four technologies in each of four industries in roughly seven years, regardless of industry or technology. When we estimate the effect of observable variables on the diffusion speed, only employment appears statistically significant. We continue to focus on energy prices, however, as a likely policy lever and compute the effect of a ten percent price increase. Based on a $95 \%$ confidence interval, we estimate that a ten percent rise in energy prices would, at most, decrease the average adoption time by about one year. 
Ignoring distinctions among technologies, our adoption model identifies two statistically significant predictors of adoption: profitability and energy prices. Based on a $95 \%$ confidence interval, these variables at most raise the rate of adoption by $3 \%$ and $10 \%$, respectively, when each variable is increased by $10 \%$. In this model, these increases in adoption directly translate into changes in the growth rate of energy efficiency.

Since aggregate energy efficiency has increased an average of $1 \%$ per year during the past few decades, raising the growth rate ten percent to $1.1 \%$ will, in fact, have little consequence for many years. At this rate, for example, energy use will have fallen by $43 \%$ instead of $39 \%$ after fifty years. Raising energy prices by $10 \%$ for the next fifty years in order to lower energy use by $4 \%$ is hardly impressive.

From these results we draw two important conclusions. Since we find that profitability has a significant effect on adoption, it will be important to consider the impact of public policy on firm revenue. Policies that immediately raise prices without allowing firms to anticipate those changes may lead to declining adoption rates if their financial health is adversely affected. Second and more significantly, these results put a damper on the idea that technology will save the day. Since energy efficiency improvement resulting from new technology adoption currently progress at only $1 \%$ per year, even a large increase in this growth rate will take many years to translate into significant reductions in aggregate efficiency. The only possibility for significant technology effects is if public policy can encourage the development of large, nonincremental technologies. 
In the remainder of the paper, we present a brief overview of the existing literature and theory on technology diffusion. We then develop an alternate model of technology adoption that establishes a link between plant-level adoption of energy-saving technologies and aggregate growth in energy efficiency. Sections 4 and 5 describe our data and results while Section 6 concludes. Additional data details are provided in an appendix.

\section{Background}

Research by economists on the subject of technology diffusion dates back more than four decades. The single most important conclusion of this work-well summarized in a recent article by Jaffe and Stavins (1994)—is that diffusion of new, economically superior technologies is a gradual rather than instantaneous process. ${ }^{1}$ Specifically, diffusion is often portrayed as a classic s-shaped or sigmoid curve over time. That is, the rate of adoption begins slowly, speeds up, then eventually slows down again as market saturation approaches.

One justification for the sigmoid curve is based on an epidemic model of diffusion. Due to a lack of knowledge or confidence, the odds that a non-user will adopt a new technology increase with the growing popularity of the technology. If we let $X_{i, t}$ represent the presence of the new technology at time $t$ for user $i$, we can write this relation as:

$$
P\left(\Delta X_{i, t}=11 X_{i, t-1}=0\right)=4 c \cdot \bar{X}_{t-1}
$$

\footnotetext{
${ }^{1}$ See Griliches (1957), Mansfield (1968), David (1966), Davies (1979), Oster (1982), Levin, Levin et al. (1987).
} 
where $\bar{X}_{i, t-1}$ is the average level of adoption-or popularity-and $c$ is a constant. $P\left(\Delta X_{i, t}=11 X_{t-1}=0\right)$ is the probability of a change in adoption status conditional on being a non-user in the previous period. Since the likelihood of being a non-user prior to time $t$ is $\left(1-\bar{X}_{i, t-1}\right)$, the overall likelihood of a change in adoption status is

$$
P\left(\Delta X_{i, t}=1\right)=4 c \cdot \bar{X}_{t-1} \cdot\left(1-\bar{X}_{t-1}\right)
$$

Note that the parameter $c$ reflects the maximum probability or speed of adoption that is obtained when the fraction of users $\bar{X}_{i, t-1}$ and non-users $\left(1-\bar{X}_{i, t-1}\right)$ are both equal to $50 \%$.

Following this intuition, it makes sense that the rate of adoption will be slow in the beginning ( $\bar{X}_{i, t-1}$ is small when there is little popularity) and in the end (1- $\bar{X}_{i, t-1}$ is small when there are few non-users). In this model, the probability of adopting the technology depends entirely on the number of other firms in the industry who have already adopted it.

The pioneering work of Griliches (1957) extends this model by establishing that the diffusion of new technology can be understood in an economic framework by allowing the rate of diffusion to be partly determined by the (expected) economic return to adoption. Mansfield (1968) then elaborates on this idea by considering the size of adopting firms, the perceived riskiness of the new technology, and the size of the required investment as potential determinants. According to this view of the world, the parameter $c$ in Equation (2) will be a function of technology specific parameters, including size of potential users.

This idea of a technology-specific diffusion speed has been explored by many authors. The size of potential users has been argued to have both positive and negative 
effects on adoption. ${ }^{2}$ Arguments for the former are based on the resources (financial, experience, expertise) associated with large firms, while arguments for the latter hinge on potentially oligopolistic market structure retarding the competitive pressures to innovate. The possibility of varying diffusion rates for different technologies has been qualitatively described by Cohen and Levin (1989) as the difference between type "A" and "B" innovations. ${ }^{3}$ Type A innovations are minor and presumably diffuse quickly while type B innovations are considerably more invasive and diffuse more slowly.

According to this line of thinking, economic factors influence the overall rate of diffusion based on idiosyncratic characteristics of the technology. Such factors do not, however, distinguish the rate of adoption by different firms. A natural alternative proposed by David (1966) is to focus on inherent differences or heterogeneity among firms. Here, differences among potential adopters-not just knowledge or confidenceis the key factor that explains the gradual diffusion process. In particular, these differences influence the value of the technology to individual firms. Such differences might include the cost of equipment, cost of learning about a new technology, cost of adapting existing processes, or future benefits of the technology.

Specifically, one can imagine a threshold above which it pays to adopt the new technology and below which it does not. The threshold differs across firms and, over time, the cost of the innovation may fall and/or the quality may improve, thereby lowering the threshold. By regressing a firm's decision to adopt on variables that describe differences among firms, one can empirically identify those differences which

\footnotetext{
${ }^{2}$ See Davies (1979), Oster (1982), and Boyd and Karlson (1993),

${ }^{3}$ See also Davies (1979).
} 
affect a firm's valuation of the innovation. There is evidence that many factors beyond traditional economic factors affect these valuations. ${ }^{4}$

There are numerous examples of environmental applications using both homogeneous and heterogeneous firm models. ${ }^{5}$ Our approach to diffusion modeling includes elements of both: we estimate probit models of adoption using firm- and plantlevel differences as determinants of the choice to adopt. However, we then convert our parameter estimates to correspond to effects on the speed parameter $c$ in Equation (2). This allows us to compare estimates across potentially dissimilar technologies.

\section{An Alternative View of Technology Adoption}

The previous discussion centers on the adoption decision concerning individual energy-saving technologies. That model allows us to explore how different factors influence the speed of adoption for individual technologies. This increase in adoption speed for individual technologies then raises aggregate energy efficiency.

However, this diffusion model fails to explain changes in the long-term growth in energy efficiency. Suppose, for example, that technology \#1 has just begun to diffuse through the economy. Technology \#2 becomes available in five years and technology \#3 after ten. All three have the capacity to raise efficiency by $10 \%$ once they are adopted by all plants. If each diffuses completely over five years, we would observe something like a $20 \%$ improvement after ten years. Yet, a policy that raises the diffusion speed and leads to complete adoption in only four years fails to change the long-term growth rate. Assuming technology \#2 still becomes available after five years and \#3 after ten, the total

\footnotetext{
${ }^{4}$ See Fazzari, Hubbard et al. (1988), Calomiris and Hubbard (1990), Carpenter, Fazzari et al. (1994), Cummins, Hassett et al. (1994), Stole and Zwiebel (1996), and DeCanio and Watkins (1998).
} 
improvement in energy efficiency after ten years is still $20 \%$, even though it arrives more quickly in the first four years of each five-year interval. The problem is that diffusion models focus on specific technologies but ignore the process by which those technologies become available-the process which eventually controls growth in energy efficiency.

We propose an alternative model that assumes technology options are always available. With a never-ending supply of technology options, adoption completely determines aggregate energy efficiency. ${ }^{6}$ Innovation occurs, but occurs in the background and is never a binding constraint: there are always opportunities to adopt energy-saving technologies. Although this view is inappropriate for the large, invasive, type B innovations noted above, it is a reasonable approximation for smaller, frequent, and minor type A technological improvements which we consider.

The advantage of this model is that it can be used to translate influences on adoption observed in a single cross-section into influences on the aggregate rate of technological change. For example, suppose that raising energy prices by $10 \%$ is estimated to increase the number of plants adopting any new technology from 100 to 105 , a 5\% rise. If technology adoption is synonymous with increased energy efficiency, and if the improvement in efficiency is basically the same regardless of the technology adopted, we can argue that this price increase would yield a 5\% improvement in energy efficiency relative to the improvement without the price increase. If these 100 technology adoptions from 1991 to 1994 yielded a 3\% rise in energy efficiency, then 105 adoptions ought to raise energy efficiency by $3.15 \%$. Assuming the increase to 105 adoptions continues in

\footnotetext{
${ }^{5}$ See Downing and White (1986), Thirtle and Ruttan (1987), Malueg (1989), Milliman and Prince (1989), Jung, Krutilla et al. (1996).

${ }^{6}$ That is, energy efficiency improvements arising from the use of new technology. Improvements could also arise from substitution among existing technologies.
} 
future periods for as long as energy prices remain $10 \%$ above their baseline, this increased growth will continue in the future.

In this pure adoption model, the relation (2) becomes inappropriate. We could imagine defining $X_{i, t}$ as the total number of technologies adopted by plant $i$ at time $t$ so $\Delta X_{i, t}$ represents the adoption of any new technology. But how could we construct the $\left(1-X_{i, t}\right)$ term? We could write $\left(N-X_{i, t}\right)$ where $N$ is the total number of available technologies. However, our view is that $N$ is enormous and-importantly-the possibility of running out of technology options is not a real concern. ${ }^{7}$

To explain the adoption of energy-saving technologies across time, we abandon the diffusion model. We retain the idea that heterogeneity among plants influences adoption. However, instead of applying this idea to a model describing adoption of a single technology, we consider how heterogeneity influences adoption of any technology.

\subsection{A model of energy efficiency}

We seek a simple model where differences among plants can explain different levels of energy efficiency but where the aggregate level and variation is easy to summarize. We assume output is fixed and plants regularly compare the cost savings from adopting energy-saving technologies to the cost of adoption. ${ }^{8}$ In order to keep the relative distribution of energy efficiency constant, we assume that adoption costs fall as aggregate efficiency rises: if plants lag behind, there is an increasing incentive to "catchup" since adoption costs are lower. Based on these assumptions, we show that the

\footnotetext{
${ }^{7}$ One could also imagine ours is an appropriate view for the moment, with the potential of running out of options somewhere in the distant future.

8 This can also be set up as imperfect competition among a large population of plants where each plant maximizes profit subject to energy as the sole cost of production.
} 
distribution of energy efficiency among plants converges to an ergodic distribution whose mean slowly rises over time.

We begin with a population of $N$ plants each producing a given amount of output $q_{n}$. Energy costs associated with production are the product of the output level, the energy use per unit of output and the price of energy:

$$
c_{n}=q_{n} \exp \left(-x_{n}\right) v_{n}
$$

where $c_{n}$ is the total energy cost, $x_{n}$ is an energy efficiency index, $\exp \left(-x_{n}\right)$ is the energy use per unit of output, and $v_{n}$ is the price of energy.

We assume that each period plants have the opportunity to invest in a discrete energy-saving project. The project raises their energy efficiency index by $\delta$ units and incurs a one-time cost of $J$. This increase in energy efficiency leads to a cost savings,

$$
\Delta c=q_{n} v_{n} \exp \left(-x_{n}\right)(1-\exp (-\delta))
$$

and a decision to invest if

$$
\Delta c>J
$$

Although the plant may have alternative energy saving opportunities, we assume that one opportunity dominates and therefore the condition (4) does, in fact, determine the overall decision to invest or not.

In addition to the possibility of alternative activities, Equation (4) also ignores the dynamic aspect of investment. Cost savings occur not just today, but in all future periods. Further, cost savings in the future hinge on future decisions about energy efficiency. A better specification would be to invest if

$$
\Delta c+\beta E\left[V\left(x_{n}\right)-V\left(x_{n-1}+\delta\right)\right]>J
$$




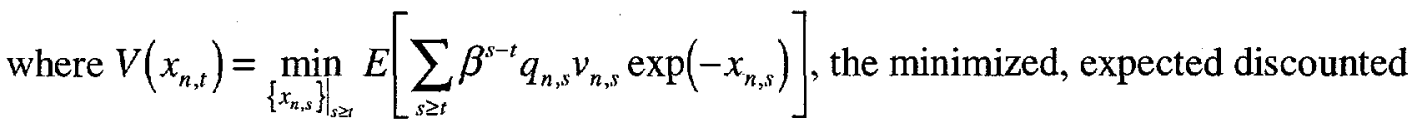
value of all future energy costs-given current efficiency $x_{n, t}$ and taking into account potential changes in output, energy prices and future efficiency. If $\beta$ is quite small or if $E\left[V\left(x_{n}\right)-V\left(x_{n-1}+\delta\right)\right]$ is proportional to $\Delta c$, this specification reduces to (4). For this analysis, we assume one of these two cases holds.

With the gradual improvement in energy efficiency, energy costs decline over time. From (3), this leads to a decline in the cost savings-since there are less costs to save. In order for adoption to continue, it must be the case that the cost of these new technologies similarly declines over time. For that reason, we specify

$$
J=j_{n} \exp (-\bar{x})
$$

where $\bar{x}$ is the average energy efficiency in the population and $j_{n}$ is a plant-specific cost parameter. This parameter is potentially affected by the cost of financing the investment, (dis)economies of scale at the plant, management efficiency, etc. There is presumably an unpredictable, random component as well. The condition for adoption can now be written:

$$
q_{n} v_{n} \exp \left(-x_{n}\right)(1-\exp (-\delta))>j_{n} \exp (-\bar{x})
$$

or

$$
\bar{x}-x_{n}>\log \left(j_{n}\right)-\log \left(q_{n}\right)-\log \left(v_{n}\right)-\log (1-\exp (-\delta))
$$

where, summarizing, $x_{n}$ measures the energy efficiency of the plant, $\bar{x}$ is the average efficiency in the industry, $q_{n}$ is the output level of the plant, $v_{n}$ is the energy price at the plant, $\delta$ is the discrete improvement in efficiency available at cost $J=j_{n} \exp (-\bar{x})$, and $j_{n}$ is a plant-specific cost parameter. 
Equation (5) is the central result of this section. It explain how different factors may influence the plant-level decision to adopt new technologies and raise energy efficiency. In particular, the further a plant lags behind the industry average in energy efficiency, the greater the likelihood of adoption. As adoption costs fall with increases in average energy efficiency, plants who resist adopting will face the same potential gains in spite of these lower adoption costs-raising the incentive to adopt. Plants who have a relatively high efficiency already have less to gain from further improvements. Higher energy prices, larger plant size and a larger improvement in efficiency all increase the likelihood of adoption, holding constant plant-specific adoption costs. Higher energy prices obviously raise the return to an energy-saving project. A larger plant collects the efficiency gain over a larger volume of energy use-again raising the return. Note that this result is reversed if adoption costs $j_{n}$ rise more than proportionally with plant size. Finally, if the same adoption cost buys a bigger improvement in energy efficiency $\delta$, this similarly raises the return and increases the likelihood of adoption.

In addition to those variables explicitly represented in Equation (5), there are many others subsumed in the plant-specific cost parameter $j_{n}$. In particular, variables affecting the cost of financing investment, potential (dis)economies of scale, management efficiency, etc. Some of these form a predicable part. We assume the others follow a random disturbance. In particular, we summarize the entire right-hand side of Equation (5) with a simple model:

$$
\log \left(j_{n}\right)-\log \left(q_{n}\right)-\log \left(v_{n}\right)-\log (1-\exp (-\delta)) \sim N\left(g\left(\mathbf{z}_{n}\right), s^{2}\right)
$$

where $\mathbf{z}_{n}$ is a vector of plant characteristic including both factors directly appearing on the right-hand side of Equation (5) (plant size, energy prices, improvement in energy 
efficiency) and factors indirectly influencing $j_{n}$ (financial and operating characteristics), the function $g()$ summarizes their influence on the likelihood of adoption, and $s$ describes the degree to which random factors influence the adoption decision. Based on this model, the likelihood of plant $n$ to adopt is given by

$$
P_{n, \text { adopt }}=\Phi\left(\frac{\bar{x}-x_{n}-g\left(\mathbf{z}_{n}\right)}{s}\right)
$$

\subsection{Aggregate behavior}

With plant level behavior given by Equation (7), we hope to show that aggregate behavior tends to a steady-state distribution of energy efficiency about an increasing level of aggregate efficiency. At this point, we assume that the size of the improvement in energy, $\delta$, is fixed. ${ }^{9}$ Therefore, based on the aggregate vector of plant characteristics $\mathbf{z}_{n}$, plant and aggregate energy efficiency, $x_{n}$ and $\bar{x}$, the fixed size of energy efficient improvements, $\delta$, and the magnitude of random elements in adoption costs $s$, Equation (7) completely describes the evolution of energy efficiency.

In order to for a steady-state distribution of energy efficiency to exist, plant characteristics must remain constant. For example, if plant characteristics diverge over time, it would be natural for the distribution of energy efficiency to diverge over time as well. Yet assuming plant characteristics are fixed is not particularly restrictive: if these characteristics instead change gradually over time, we simply recognize that the steadystate energy efficiency distribution will be gradually changing as well. With this assumption of time-invariance, we summarize the effect of plant characteristics on adoption by a parameter $g_{n}=g\left(\mathbf{z}_{n}\right)$. 
Writing the efficiency level of plant $n$ at time $t$ at $x_{n, t}$, we can rewrite (7) as

$$
P_{n, \text { adopt }}=\Phi\left(\frac{\bar{x}_{t}-x_{n, t}-g_{n}}{s}\right)
$$

where $\bar{x}_{t}$ is similarly the mean efficiency at time $t$. Letting $F_{t}$ be the cumulative

distribution of $g_{n}+x$ at time $t$, we can easily compute the probability distribution at time $t+1$ as:

$$
F_{t+1}\left(g_{n}+x\right)=F_{t}\left(g_{n}+x\right)-\int_{g_{n}+x-\delta}^{g_{n}+x} \Phi\left(\frac{\bar{x}_{t}-y}{s}\right) d F_{t}(y)
$$

That is, the probability that the sum of the plant parameter $g_{n}$ plus energy efficiency $x$ is below a certain level at time $t+1, F_{t+1}\left(g_{n}+x\right)$, equals the probability it was below that level in the previous period, $F_{t}\left(g_{n}+x\right)$, minus the probability of being within $\delta$ of $f_{n}+x$ and adopting a new technology.

An important observation is the role of the plant effect $g_{n}$ which, from Equation (6), summarizes the net cost of technology adoption. This effect shifts the distribution of a particular plant's likely energy efficiency relative to other plants. A particularly high value of $g_{n}$ indicates that the energy efficiency of that plant is likely to be lower. Why? A high value of $g_{n}$ reflects a higher net cost of adoption. Over time, we would expect plants with higher net adoption costs to lag behind.

Recalling that our goal is to look consider long-run behavior, we note that the sequence of probability function defined by (8) cannot converge. From (8), $F_{t+1}(x)<F_{t}(x)$. However, suppose we consider the distribution of plants about their

\footnotetext{
${ }^{9}$ One interpretation of this assumption is to recall that we are limiting ourselves to the case of gradual improvements to efficiency. Therefore a small and roughly constant improvement factor is appropriate.
} 
mean. That is, given $\bar{x}_{t}$ define $F_{t}^{*}\left(g_{n}+x-\bar{x}_{t}\right)=F_{t}\left(g_{n}+x\right)$, we can compute the change in mean over time assuming the $g_{n}$ 's are fixed:

$$
\Delta \bar{x}_{t+1}=\bar{x}_{t+1}-\bar{x}_{t}=\delta \cdot \int_{-\infty}^{\infty} \Phi\left(\frac{-y}{s}\right) d F_{t}^{*}(y)
$$

where $\int_{-\infty}^{\infty} \Phi\left(\frac{-y}{s}\right) d F_{t}^{*}(y)$ is just the aggregate probability of adoption and define

$$
F_{t+1}^{*}\left(g_{n}+x-\bar{x}_{t+1}\right)=F_{t}^{*}\left(g_{n}+x-\bar{x}_{t}\right)-\int_{g_{n}+x-\bar{x}-\delta}^{g_{n}+x-\bar{x}} \Phi\left(\frac{-y}{s}\right) d F_{t}^{*}(y)
$$

or simplifying,

$$
F_{t+1}^{*}(z)=F_{t}^{*}\left(z+\Delta x_{t+1}\right)-\int_{z+\Delta x_{t+1}-\delta}^{z+\Delta x_{t+1}} \Phi\left(\frac{-y}{s}\right) d F_{t}^{*}(y)
$$

Note that

$$
\bar{x}=E_{g_{n}}\left[\int x d F^{*}\left(g_{n}+x-\bar{x}\right)\right]=E_{g_{n}}\left[\int\left(y+\bar{x}-g_{n}\right) d F^{*}(y)\right]=\int y d F^{*}(y)+\bar{x}-E\left[g_{n}\right]
$$

so that the mean of the distribution given by $F^{*}$ is the mean of the plant effects $g_{n}$.

Equation (10) provides a recursion for determining the distribution of $g_{n}+x$

about the mean value of $x$ over time. It is trivial to show that if $\Delta x_{t+1}$ is defined as in (9) then $F_{t+1}$ given by (10) will have the same mean as $F_{t}$. Otherwise, the recursion depends only on $s$ and $\delta$. This recursion is also be simplified by differentiating (10), writing it in terms of the probability density function $f^{*}(z)=\frac{d F^{*}(z)}{d z}$ :

$$
f_{t+1}^{*}(z)=f_{t}^{*}(z)-\left.\Phi\left(\frac{-y}{s}\right) f_{t}^{*}(y)\right|_{z-\delta} ^{z}
$$


Figure 1: Steady-state Distribution of Efficiency for Various Parameter Combinations
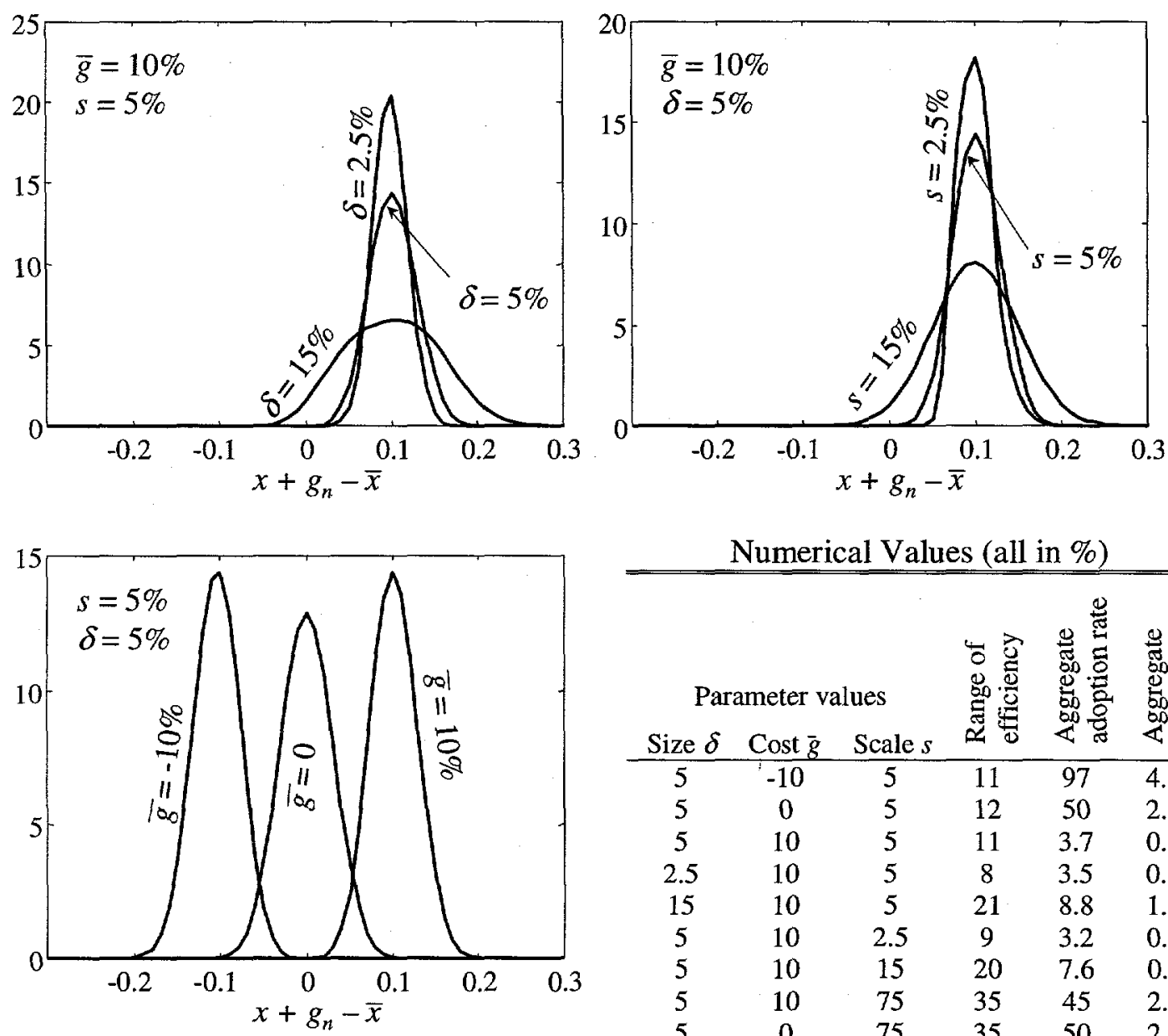

\begin{tabular}{|c|c|c|c|c|c|}
\hline \multicolumn{6}{|c|}{ Numerical Values (all in \%) } \\
\hline \multicolumn{3}{|c|}{ Parameter values } & \multirow{2}{*}{ 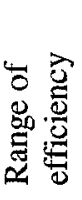 } & \multirow{2}{*}{ 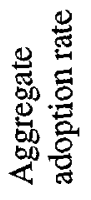 } & \multirow{2}{*}{ 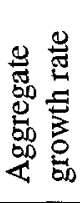 } \\
\hline Size $\delta$ & Cost $\bar{g}$ & Scale $s$ & & & \\
\hline 5 & -10 & 5 & 11 & 97 & 4.8 \\
\hline 5 & 0 & 5 & 12 & 50 & 2.5 \\
\hline 5 & 10 & 5 & 11 & 3.7 & 0.2 \\
\hline 2.5 & 10 & 5 & 8 & 3.5 & 0.1 \\
\hline 15 & 10 & 5 & 21 & 8.8 & 1.3 \\
\hline 5 & 10 & 2.5 & 9 & 3.2 & 0.2 \\
\hline 5 & 10 & 15 & 20 & 7.6 & 0.4 \\
\hline 5 & 10 & 75 & 35 & 45 & 2.2 \\
\hline 5 & 0 & 75 & 35 & 50 & 2.5 \\
\hline 5 & -10 & 75 & 35 & 55 & 2.8 \\
\hline
\end{tabular}

Figure 1 shows the limiting distribution for several combinations of $\bar{g}=E\left[g_{n}\right], s$, and $\delta$, as well as a tabulated values for the aggregate adoption rate and growth in efficiency. These distributions are obtained numerically from the repeated application of (11) to an arbitrary initial distribution $f_{0}{ }^{10}$ The bottom right panel indicates the variation in energy efficiency, the average likelihood of adoption, and the growth rate of energy

${ }^{10}$ As long as $f_{0}$ is continuous, convergence was always obtained. 
efficiency, all at the steady state. The growth rate of energy efficiency is, by construction, equal to the rate of adoption times the size of the innovation $\delta$.

Row two, for example, indicates that with $\delta=0.05, \bar{g}=0$ and $s=0.05$, the steady-state distribution of energy efficiency will exhibit a spread of roughly $11 \%$ between the most and least efficient plants. Further, the average adoption rate in the population will be $50 \%$ and the aggregate growth rate in energy efficiency will be $2.5 \%$. Based on our data, where roughly $50 \%$ of the plants adopt at least one new technology over the period 1991-1994, and with an aggregate annual improvement in energy efficiency of $1 \%$, these parameters would appear plausible. Note, however, that we have no direct knowledge of the third parameter $s$, affecting the variation in energy efficiency within the industry. ${ }^{11}$

\subsection{Implication of lower net adoption costs}

A frequent goal of government policy is to lower the net costs of technology adoption (or innovation) in order to spur greater energy efficiency. From Equation (6), that might come about from either directly lowering gross adoption costs $j_{n}$ or indirectly from raising energy prices $v_{n}$. The implication of lower net adoption costs can be understood in the context of the numerical results in Figure 1. In particular, note that a $10 \%$ increase in average adoption costs-indicated by $\bar{g}$ falling by $10 \%$--can have a range of effects. When $s$ is small (first two rows of results), growth in energy efficiency rises by nearly $100 \%$, from $2.5 \%$ to $4.8 \%$ each period. Yet when $s$ is large (last two rows

\footnotetext{
${ }^{11}$ When we attempt to measure energy efficiency at the plant level (based on $\mathrm{BtU}$ energy use per $\$$ of sales, per employee or per production worker), we find the standard deviation of log efficiency to be between 1 and 1.5. The implication of these numbers, that some plants use 10 or even 100 times as much energy as other plants, seems implausible.
} 
of results), growth in energy efficiency changes by a marginal amount, from $2.5 \%$ to $2.8 \%$ each period.

The parameter $s$ reflects the random variation in costs beyond the predictable deviations given by $g_{n}$. When $s$ is small relative to the magnitude of $g_{n}$, it means that adoption is determined by observable variables. For example, when $\bar{g}$ is $10 \%$ and $s$ is only $5 \%$, the average adoption rate is $3 \%$. On the other hand, when $s$ is large compared to $\bar{g}$, say $\bar{g}=10 \%$ but $s=75 \%$, the adoption rate is $45 \%$. In the first case, $g$ is determining adoption (or the lack of it) while in the second case $g$ is relatively unimportant and adoption is random.

The consequence of a small $s$ is that plants will be relatively concentrated at the steady state. This is evident from the upper right panel of Figure 1. More importantly, small $s$ implies that shifts in $\bar{g}$ owing to aggregate policy intervention should have potentially enormous effects, perhaps moving adoption from rates near zero to rates near $100 \%$. When $s$ is large, such policies have less effect simply because random variation is more responsible for adoption than observable, and possibly manipulable, variables.

\subsection{Determinants of adoption}

Based on (6), there are two obvious plant characteristics influencing adoption: energy prices $\left(v_{n}\right)$ and plant size $\left(q_{n}\right)$. Both plant size and energy price should have positive effects on adoption because both raise the energy bill and hence the potential savings from higher energy efficiency. ${ }^{12}$ Equation (6) also shows that projects with larger efficiency improvements $(\delta)$ will also have a higher likelihood of adoption.

\footnotetext{
${ }^{12}$ Any positive effects of plant size on adoption cost would counteract the positive effect on cost-savings.
} 
Other plant characteristics influence adoption by influencing the cost of the project $j_{n}$. In this paper, we focus on financial characteristics of parent firms as potentially important determinants of project cost. The idea is simple: healthier firms will have more resources and easier access to credit than firms that are less healthy. This lowers the cost of any investment project. Our empirical work focuses on two measures of health: working capital and net profits.

The only remaining parameter in (6) is the size of the innovation in terms of the improvement to energy efficiency, $\delta$, which we assume to be constant. As noted earlier, there are also dynamic issues which we have subsumed into the cost parameter $j_{n}$. These features might include other characteristics of the technology, its lifespan, flexibility, and maintenance requirements. They might also include other characteristics of the plant, such as capital stock vintage.

Summarizing, the explanatory model of the firm's decision to make a discrete investment—specifically in energy efficient equipment-is a function of the equipment, plant and firm characteristics listed below (only some of which we have access to):

\section{Equipment}

- Price

- Expected life

- Efficiency

- Maintenance requirements

\section{Plant}

- Prices of factor inputs, especially energy

- Rate of plant utilization

- Efficiency of existing capital stock

- Size

\section{Firm}

- Working capital

- Profitability 
- Other balance sheet and income statement characteristics influencing the private market cost of finance

\section{Data}

The data for this research come from several large plant-level data sets collected periodically by the Census Bureau and the Department of Energy. Prior work by several of the principal investigators has linked together a number of these data sets to create a large sample of plants. The present work focuses on four energy and pollution intensive industries: petroleum, plastics, pulp and paper, and steel. Direct carbon emissions of these four industries account for more than one-fourth of total carbon emissions from the manufacturing sector (not including electricity consumption).

The central data set is the Longitudinal Research Database (LRD), a pooled crosssection time series comprised of the annual establishment (plant) responses to the Annual Survey of Manufactures (ASM) and Census of Manufactures (CM). The LRD contains detailed information on outputs and inputs at the plant level. We derive regional energy

price indices using energy price data from the State Energy Price and Expenditure Report 1995 DOE/EIA (1998).

Of particular interest to this research are the 1991 and 1994 Manufacturing Energy Consumption Surveys (MECS), collected by the Department of Energy. These surveys contain information on installed energy-saving technologies, asking detailed questions about the presence of both industry-specific and general technologies in the plant. In this study we focus on the four general energy-saving technologies: computerized climate controls (HVAC), computerized process controls (Process), waste- 
heat recycling (Wst Ht) and adjustable speed motors (Motors) (see additional technology description at the end of the Appendix).

One of the novel aspects of this research is the focus on firm-level investment decision making. Through the use of parent firm identifying codes in the LRD we are able to link our existing plant-level data set with financial information from the parent firms, available since 1983 in the Quarterly Financial Report (QFR), based on the work of Long and Ravenscraft (1993). This information permits us to examine the theoretically defined roles of the parent firms' financial characteristics and corporate policies as factors influencing technology adoption decisions.

\section{$5 \quad$ Estimation}

We have discussed two alternative models of technology adoption: one which focuses on the adoption speed of individual technologies and another which focuses on overall adoption rates of arbitrary new technologies. In both cases, observable characteristics of the plants influence adoption. In this section we estimate those influences in both models and compare the results

\subsection{Diffusion of individual technologies}

Earlier discussions on technology diffusion established Equation (2) as a descriptive relation for the change in adoption status over time. This differential equation can be solved for the path of adoption over time to yield:

$$
p(t)=\frac{\exp \left(4 c \cdot\left(t-t_{0}\right)\right)}{1+\exp \left(4 c \cdot\left(t-t_{0}\right)\right)}
$$


where $t_{0}$ is a constant of integration and represents the half-way point where one-half of the potential users have adopted the technology. Since our data consists of adoption data at two distinct points in time, 1991 and 1994, we can compute the parameter $c$, measuring the speed of diffusion. In particular, given $p(0)=p_{0}$ and $p(1)=p_{1}$, we can compute

$$
4 c=\log \left(1 / p_{0}-1\right)-\log \left(1 / p_{1}-1\right)
$$

If $p_{0}$ and $p_{1}$ are sufficiently close, this can be approximated using (1) with the rate of adoption among non-users, $P\left(\Delta X_{i, t}=1 \mid X_{i, t-1}=0\right)$, divided by the fraction of potential users that have already adopted, $\bar{X}_{t-1}$. The left panel of Table 1 computes estimates of the diffusion speed $c$ for each of the sixteen technologies-sector combinations available in our data.

Remarkably, the diffusion speed is essentially the same for almost all technologysector combinations. That is, with sixteen independent estimates of the diffusion speed, a chi-squared test of equality fails to reject at any level of significance. Given the 3-year interval in the model (1991-1994), the estimated value, $c=0.22$, indicates that the middle half of the population adopts the technology in about 7 years. ${ }^{13}$ Recall that the parameter $c$ indicates the rate of adoptions per 3-year period halfway through the diffusion process, when the fraction of users and non-users are both $50 \%$. Roughly one-quarter adopt before that seven-year period and another quarter adopt afterward.

Of course, our real interest is in how an array of explanatory variables influence the diffusion speed. We do this by estimating a probit models for the probability of adoption in 1994 among non-users in 1991 with each of the sixteen technology-sector

\footnotetext{
${ }^{13}$ Note that $\frac{50 \%}{0.22(\% / \text { period })} \times 3($ years $/$ period $) \approx 7$ years. To get the exact value, we evaluate the logit function.
} 
combinations. Normally, the probit estimation would then be used to compute the effect of explanatory variables on the this conditional probability of adoption. We instead scale the estimates to reflect the effect of explanatory variables on the speed of diffusion. For example, the estimated coefficient on working capital in the first regression involving computerized HVAC technology in the Pulp and Paper sector is 3.46 with a standard error (s.e.) of 2.24. The density of a standard normal distribution evaluated at the mean of the predicted value $x^{\prime} \beta$, where $x$ are the right-hand side variables and $\beta$ are the estimated coefficients, is 0.237 . Multiplying the original estimates by this density yields 0.82 (s.e. 0.53 ) as the estimated effect on the conditional probability of adoption. That is, raising working capital (expressed as a fraction of total assets) by $1 \%$ would raise the likelihood of adopting computerized HVAC technology by $0.82 \%$ - conditional on not having the technology in 1991.

To compute the effect on speed, we need to multiply by the derivative of speed with respect to this conditional probability. From (12) and the fact that $p_{1}-p_{0}=h\left(1-p_{0}\right)$ where $h$ is the conditional probability or hazard rate, this derivative can be computed as

$$
\frac{d c}{d h}=\frac{\left(1-p_{0}\right)}{4 p_{1}\left(1-p_{1}\right)}
$$

In this case, with $p_{0}=0.13$ and $p_{1}=0.29$, we have $d c / d h=1.06$. Multiplying this by 0.82 , we obtain 0.87 (s.e. 0.56 ) which is what we see, within rounding error, in the first row of Table 1.

We focus on the speed parameter instead on the conditional probability because the conditional probability of adoption (hazard rate) is sensitive to the initial popularity of 
the technology in the diffusion model. Technologies such as computerized HVAC should have lower hazard rates, relative to computerized process controls, for example, because the initial popularity in 1991 is lower-this is exactly what we see in Table 1. Yet the speed parameter is relatively constant. This allows us to make comparisons across technologies and sectors. In particular, we can average our results across technologies/sectors in order to obtain more precise estimates. ${ }^{14}$

The right panel of Table 1 presents the effects of selected independent variables on diffusion speed: working capital as a share of total assets (work cap), energy prices in $\$ / \mathrm{BtU}$ (en prices), the log of employment (employ), and after-tax profit as a share of total revenue (profit). We observe three instances where employment (e.g., plant size) has a statistically significant coefficient, two where energy prices are significant, and one where profit is significant. One of the two significant energy price coefficients has a negative sign-the opposite of what one would expect. At the bottom of the table, we average the sixteen estimates two ways: weighting each estimate equally and weighting the observations in proportion to the inverse of their variance (e.g., the precision) providing an average with the lowest possible variance. Only employment is significant when averaged across all estimates.

These results provide no convincing evidence that energy prices or firm financial health influence diffusion speed. While one might expect the small sample size to hinder estimates for individual technologies in particular sectors, the averages at the bottom are no more convincing even though the sample size is effectively over six hundred observations (the sum of the sixteen individual sample sizes). Alternative models where

\footnotetext{
${ }^{14}$ This approach of making comparisons across potentially similar samples is the idea behind hierarchical models. See Chapter 5 of Gelman, Carlin et al. (1995).
} 
the data are directly pooled and where different versions of the right-hand side variables are included produce similar results.

Despite the statistical insignificance, we can still assess the potential policy relevance of the variables by considering the confidence interval. Suppose we take the largest coefficient value inside a standard $95 \%$ confidence interval for a energy prices. This would be $0.005+2 \times 0.011=0.027$, based on the precision weighted averages. We then consider how much energy prices might be influenced by a policy change. For example, a $10 \%$ rise in energy prices might be the most anyone is willing to contemplate. Using this high-end estimate of the price coefficient, we would find that a $10 \%$ rise in energy prices would lead to a

$$
0.027 \times 0.10 \times 5.56=0.015
$$

(coefficient) $(10 \%)$ (mean price)

effect on the diffusion speed.

Based on the average observed diffusion speed of 0.22 , this represents an increase of $7 \%$. In other words, picking any point along the diffusion curve, adoption will be occuring $7 \%$ faster. For example, imagine two technologies are just beginning the diffusion process with users comprising only one percent of the population. One diffuses at a speed of 0.22 , the other at 0.0235 . On average, it will take 15.7 years for the remaining plants to adopt when the speed is 0.022 ; this time falls to 14.7 when the speed is 0.0235 . Thus, a ten percent rise in prices might arguably lead plants to adopt a new technology a year earlier. ${ }^{15}$ Except for employment, which is unlikely to be a true policy lever and has a slightly larger effect, the remaining variables have an even smaller effect.

\footnotetext{
${ }^{15}$ Note that our choice of starting points for this comparison, $1 \%$, is somewhat arbitrary. Picking a later starting point lowers the difference in average adoption time. For example, if we start the two technologies at $50 \%$, the higher diffusion speed lowers adoption time by only 4 months.
} 
Is this an important effect? At most, this is equivalent to moving up each user's adoption by a year. While this obviously leads to cost savings, this is not the kind of improvement that will bring forth previously unattainable goals in energy use. What we need to understand is how the overall adoption rate-comprising both diffusion and innovation-will change.

\subsection{Growth in energy efficiency}

The alternate model of technology adoption we present focuses on the generic adoption of new technologies rather than the particular progress of a single one. The advantage of this model is that we are able to derive aggregate results from a behavioral model at the plant level. In particular, while diffusion model is cursed because it fails to explain the process by which new technologies arrive, our model of energy efficiency presumes a ever-present menu of technology options. The adoption process alone determines the pace of aggregate efficiency growth.

In this model, technology adoption is assumed to entail a similar increase in efficiency regardless of the technology chosen. In a given period, a certain fraction of plants, weighing the costs and benefits of adoption, choose to adopt a new technology. Changing the variables that influence the costs and benefits-price, financial health, plant size, etc.- presumably will influence the number of plants choosing to adopt.

Our data consists of a single three-year period over which we observe whether or not a sample of plants has chosen to adopt any new technologies. Within our sample, roughly half choose to adopt new technologies and half do not. Based on the observed cross-sectional variation in prices, size, profitability and working capital, we can estimate how those variables are likely to affect the overall adoption rate. 
Table 2 presents these adoption results. The main difference between Table 2 and Table 1 is that Table 2 estimates a probit model using the adoption of any technology as the dependent variable, rather than the adoption of a particular technology. This means that for each industry, we can estimate only a single model, compared to the estimates for each of four technologies in Table 1. The other difference between the tables is that Table 2 presents the effect of each variable on the conditional probability of adoptionwhich was only the first step of the calculations in Table 1 in order to compute the effect of each variable on diffusion speed. For comparison, we present the average value of the estimates in Table 1 (in terms of their effect on adoption probability, not speed) at the bottom of Table $2 .^{16}$

We estimate the adoption model both with and without controls for the presence of particular technologies in 1991. We also compute averages across the four industries as well as estimating pooled models with industry controls. There are minor discrepancies between the averaged and pooled estimates and the presence of technology controls has little effect except for the employment coefficient.

These results indicate that profit, expressed as a fraction of total revenue, has a statistically significant impact on adoption. Average profit is around $5 \%$ of revenues. A ten percent increase would raise it by $0.5 \%$. Based on a central coefficient estimate of about 1.5 , this would raise the likelihood of adoption by about $0.75 \%$. Using a high coefficient estimate of 3.0 , the effect would be a $1.5 \%$ rise in the likelihood of adoption. Although a doubling of profit could raise adoption by $15 \%$, from a policy standpoint-

\footnotetext{
${ }^{16}$ While we might expect these estimates to be similar, they are subject to considerable variation based on the variation already observed in Table 1 . In particular, it is unclear how the different models end up "weighting" the wide-ranging effects reflected in the estimates for individual technologies and sectors.
} 
where a tax rebate or investment incentives might raise profit by $10 \%$-these results suggest a rather small, though statistically significant, effect.

Prices have a statistically significant effect in the model without technology controls, but fade in the model with them. Using a central coefficient estimate of around 0.05 and a ten percent rise in average energy prices-from $\$ 5.50 / \mathrm{BtU}$ to $\$ 6.00$, or $\$ 0.50-$ we would expect a $2.5 \%$ rise in adoption. A high end coefficient estimate of 0.10 would indicate a $5 \%$ rise in the adoption rate. Compared to the profit effect, these are several times larger. But could they make a difference in terms of aggregate energy efficiency growth?

Consider that the average adoption rate in the sample is $50 \%$. Therefore, a $5 \%$ increase in the adoption rate reflects a $10 \%$ increase in the actual number of plants adopting new technologies; e.g., 50 plants adopted before, 55 adopt now-a $10 \%$ rise. Based on our model, the adoption rate is proportional to growth in energy efficiency: from Equation (9) $\Delta \bar{x}=\delta \cdot P($ adoption) where $\Delta \bar{x}$ is the aggregate growth in energy efficiency and $\delta$ is the change in percent change in energy efficiency per adoption. Given the proportional relation, a $10 \%$ rise in adoptions raises the growth rate by $10 \%$. Based on our assumptions, this increased growth rate will remain in effect so long as the price increase remains in effect. Therefore, we would expect this $10 \%$ increase in the growth rate to persist.

Although a $10 \%$ increase in energy efficiency growth is significant, it does not suggest a panacea for environmental problems. Based on a historical growth rate of 
about $1 \%$ per year, ${ }^{17}$ this would translate into an additional one-tenth of one percent of growth-an increase to $1.1 \%$ per year. Over fifty years, a $1 \%$ growth rate would reduce energy usage by $39 \%$. A $1.1 \%$ growth rate would reduce energy use by $43 \%$. With energy prices $10 \%$ higher than the baseline, total energy costs would still be higher relative to the baseline with no price increase, even after fifty years.

The remaining variables have negligible effects. Based on a central estimate of 0.35 , a ten percent rise in average working capital from 0.09 to 0.10 (as a percent of total assets) would raise adoption by $0.01 \times 0.35=0.35 \%$. Using 0.10 as a central estimate of the effect of log employment on adoption, a ten percent rise in employment would have a $0.10 \times 0.10=1 \%$ effect on adoption

Unlike the other variables, the coefficient on employment is significantly affected by the presence or absence of controls for technologies in 1991. However, this is not surprising: employment is consistently a strong predictor of adoption-both between 1991 and 1994 and prior to 1991 . Yet the adoption of technologies prior to 1991 makes it more difficult to adopt between 1991 and 1994-there are fewer technologies to adopt. Therefore, the direct, positive effect of employment of on adoption from 1991 and 1994 is counterbalanced with an indirect, negative effect of employment via the likelihood of having already adopted some technologies prior to 1991. Controlling for adoptions prior to 1991 eliminates this countervailing effect. Variables that change over time-like prices and profitability - are not subject to this effect since their values in 1991 are not indicative of their values, and hence the direction of their influence on adoption, in the past.

\footnotetext{
${ }^{17}$ In 1959 energy consumption was $19,048 \mathrm{BtUs} /(\$$ real GDP) versus 13,475 in 1995 . This represents an annual decline of $1 \%$ per year.
} 


\subsection{Problems with adoption model}

The preceding comment about controls for adoption prior to 1991 points to an important flaw in the adoption model. We have, at most, information about the potential adoption of four technologies. ${ }^{18}$ Our model is predicated on the idea that there are always a menu of potential energy-saving opportunities, not just four. Further, plants that have already adopted three technologies in $1991 \mathrm{can}$, at most, adopt the single missing technology between 1991 and 1994.

While problematic in estimating the overall adoption rate, this does not introduce an obvious bias in the estimated effect on energy efficiency growth. In particular, we estimate the effect of various independent variables on the probability of adoption within the pool of adoptions we can measure. Although we miss the effect on technologies beyond the four in this study, there is no reason to believe that the effect on those technologies would be different than the effect on the ones we do observe. That is, suppose we find a ten percent price increase raises the adoption rate from 50 to 55 out of 100 possible adoptions. With a larger pool of 1000 possible adoptions-larger both in terms of plants and technologies-our best guess is that there would be a corresponding increase from 500 to 550 adoptions. Thus we find no reason to imagine it should be higher or lower. Of course, to the extent that the technologies and sectors we consider are qualitatively different than the broader population, this assumption may fail.

\footnotetext{
${ }^{18}$ We have additional information about roughly a dozen industry-specific technologies which we have not used.
} 


\section{Conclusion}

There have been two main goals in this paper. The first has been to investigate the role of different plant and firm-level characteristics in the decision to adopt energysaving technologies. The second has been to consider the importance of these effects in terms of long-run aggregate energy efficiency. To reach the first goal, it was only necessary to consider the traditional model of technology diffusion and ask how different variables might influence the speed of diffusion. To reach the second, it was necessary to first develop a model that could explain a relationship between plant level adoption decisions and long run aggregate energy efficiency. This model indicated that individual plants will tend to a steady state distribution around the mean level of energy efficiency, which itself will grow at a constant rate. In this equilibrium, the aggregate growth rate in energy efficiency equals the average adoption rate, times the efficiency improvement per adoption.

Estimating the diffusion model, we drew several conclusions. Surprisingly, the speed of diffusion was relatively constant across the four technologies and four industries in our sample. Through the middle portion of the diffusion process, fifty percent of the plants adopt each of the new technologies in roughly seven years. A quarter adopt the technology before this period, and a quarter after it. With the exception of employment, none of the variables we considered show a consistent and statistically significant impact on the speed of diffusion. Since energy prices are an obvious instrument with which policymakers might try to influence adoption, we use the estimated $95 \%$ confidence interval on the price coefficient to estimate the maximum effect prices might have on diffusion. We estimate that a ten percent increase in prices would, at most, increase the 
diffusion speed by $7 \%$. That would, on average, lower the time it takes to adopt a new technology by about a year.

The problem with the diffusion model becomes clear during its estimation. We expend considerable effort to estimate the effect of prices on the speed of diffusion, but this does not help us identify an effect on aggregate energy efficiency. In a model focused on individual technologies, long run growth in energy efficiency will depend on the rate at which new technologies become available, not how fast each one diffuses.

In our proposed adoption model, we pool the information on adoption across all the technology and estimate a model where the dependent variable is adoption of any technology. These results are more promising, with both profitability and energy prices showing a statistically significant and positive effect on adoption. The more generous, high-end parameter estimates indicate that a ten percent rise in profitability would increase the likelihood of adoption by $1.5 \%$ while a ten percent rise in energy prices would increase the likelihood of adoption by $5 \%$. With an overall adoption rate of $50 \%$ over the 3-year period we study, this amounts to $3 \%$ and $10 \%$ increases in the actual number of plants adopting any new technology for a $10 \%$ increase in profitability and energy prices, respectively.

From our model, this can be extrapolated directly to increases in the current and future growth rate of energy efficiency, assuming the changes in profitability and energy prices persist. That is, a ten percent rise in profitability and energy prices should raise the growth rate in energy efficiency by $3 \%$ and $10 \%$, respectively. Although these are interesting numbers, it is important to note that they do not represent an equivalent reduction in actual energy use. Historically, energy efficiency has been improved by 
roughly $1 \%$ per year. Raising this to $1.1 \%$ means that after fifty years, we would expect a $43 \%$ fall in energy use instead of $39 \%$. That is, raising energy prices by $10 \%$ generates only a $4 \%$ reduction in energy use due to extra improvements to energy efficiency even after 50 years.

Our conclusion is that many variables influence the adoption of new technologies. Along with plant size (which is not typically manipulable by public policy), energy prices and profitability are both observed to raise the rate of energy-saving technology adoption. This has important implications for the design of regulatory policies: raising the price of energy could lead to a short-run decline in energy-saving investments if firm financial health is adversely affected.

We also find the magnitude of these effects on adoption is potentially large: using the most generous possible estimates, a ten percent rise in energy prices could raise the adoption rate by ten percent. However, adoption of new technologies currently improves energy efficiency by only $1 \%$ per year. Raising that growth rate by $10 \%$--to $1.1 \%$--makes little difference even after fifty years. Therefore a significant improvement in the rate of adoption has little consequence for actual energy use for many years.

While this research casts doubt on the idea that technology offers the promise of low cost, pollution free production in the future, it does not completely reject the idea. This research has focused on incremental technologies that do not fundamentally change the way plants operate. These were referred to as Type B in the literature. Although these results suggest that public policy is unlikely to generate significant improvements based on incremental technology adoption, it is entirely possible that larger, Type A innovations could be encouraged along with the incremental technologies. Perhaps the 
gains from larger, discrete improvements in technology could, in fact, alter the trade-off between high cost environmental protection and the risk of significant environmental damage. 
Table 1: Diffusion Model Estimates

\begin{tabular}{|c|c|c|c|c|c|c|c|c|c|c|}
\hline & \multicolumn{5}{|c|}{ Speed estimation } & \multicolumn{5}{|c|}{ Probit estimation of adoption in 1994} \\
\hline & $\begin{array}{c}\text { Total } \\
\text { number } \\
\text { of plants }\end{array}$ & \multicolumn{2}{|c|}{$\begin{array}{l}\text { Fraction with } \\
\text { technology in: }\end{array}$} & $\begin{array}{l}\text { hazard } \\
\text { rate }\end{array}$ & $\begin{array}{c}\text { diffusion } \\
\text { speed }\end{array}$ & $\begin{array}{c}\text { speed i } \\
\text { work cap } \\
(\%) \\
\end{array}$ & $\begin{array}{l}\text { en prices } \\
\text { en due } \\
(\$ \mathrm{BtU})\end{array}$ & $\begin{array}{l}\text { to a unit che } \\
\text { employ } \\
(\%)\end{array}$ & $\begin{array}{c}\text { ge in: } \\
\text { profit } \\
(\%) \\
\end{array}$ & $\begin{array}{c}\text { sample } \\
\text { size }\end{array}$ \\
\hline HVAC & 126 & 0.13 & 0.29 & 0.18 & $\begin{array}{l}0.25 * \\
(0.05)\end{array}$ & $\begin{array}{r}0.88 \\
(0.57)\end{array}$ & $\begin{array}{l}-0.01 \\
(0.03)\end{array}$ & $\begin{array}{l}0.11 \text { * } \\
(0.05)\end{array}$ & $\begin{array}{r}0.04 \\
(0.79)\end{array}$ & 110 \\
\hline 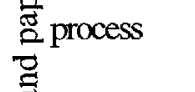 & 126 & 0.71 & 0.87 & 0.57 & $\begin{array}{l}0.26 * \\
(0.05)\end{array}$ & $\begin{array}{l}-0.42 \\
(0.73)\end{array}$ & $\begin{array}{l}-0.03 \\
(0.04)\end{array}$ & $\begin{array}{r}0.11 \\
(0.07)\end{array}$ & $\begin{array}{r}2.53 \\
(1.47)\end{array}$ & 37 \\
\hline $\begin{array}{l}\text { 韋 waste heat } \\
\text { ह }\end{array}$ & 126 & 0.63 & 0.76 & 0.35 & $\begin{array}{l}0.15 * \\
(0.04)\end{array}$ & $\begin{array}{r}0.05 \\
(0.57)\end{array}$ & $\begin{array}{r}0.02 \\
(0.03)\end{array}$ & $\begin{array}{r}0.05 \\
(0.04)\end{array}$ & $\begin{array}{l}-0.69 \\
(0.78)\end{array}$ & 46 \\
\hline motors & 126 & 0.76 & 0.91 & 0.63 & $\begin{array}{l}0.30 * \\
(0.07)\end{array}$ & $\begin{array}{r}0.30 \\
(1.03)\end{array}$ & $\begin{array}{r}0.01 \\
(0.06)\end{array}$ & $\begin{array}{l}-0.07 \\
(0.07)\end{array}$ & $\begin{array}{r}0.74 \\
(1.31)\end{array}$ & 30 \\
\hline HVAC & 55 & 0.15 & 0.22 & 0.09 & $\begin{array}{l}0.12 * \\
(0.06)\end{array}$ & $\begin{array}{r}0.17 \\
(0.16)\end{array}$ & $\begin{array}{l}0.07 * \\
(0.03)\end{array}$ & $\begin{array}{r}0.02 \\
(0.02)\end{array}$ & $\begin{array}{l}-0.12 \\
(0.48)\end{array}$ & 47 \\
\hline$\underset{\mathbb{D}}{\mathbb{S}}$ process & 55 & 0.60 & 0.89 & 0.73 & $\begin{array}{l}0.42 * \\
(0.10)\end{array}$ & $\begin{array}{r}1.18 \\
(0.88)\end{array}$ & $\begin{array}{r}0.07 \\
(0.12)\end{array}$ & $\begin{array}{l}-0.09 \\
(0.13)\end{array}$ & $\begin{array}{r}7.24 \\
(4.54)\end{array}$ & 22 \\
\hline waste heat & 55 & 0.36 & 0.53 & 0.26 & $\begin{array}{c}0.17^{*} \\
(0.05)\end{array}$ & $\begin{array}{r}0.16 \\
(0.32)\end{array}$ & $\begin{array}{l}-0.02 \\
(0.06)\end{array}$ & $\begin{array}{r}0.03 \\
(0.06)\end{array}$ & $\begin{array}{l}-0.63 \\
(0.82)\end{array}$ & 35 \\
\hline motors & 55 & 0.44 & 0.75 & 0.55 & $\begin{array}{c}0.33 * \\
(0.07)\end{array}$ & $\begin{array}{r}0.94 \\
(0.52)\end{array}$ & $\begin{array}{l}-0.06 \\
(0.10)\end{array}$ & $\begin{array}{r}0.00 \\
(0.07)\end{array}$ & $\begin{array}{r}-0.40 \\
(1.27)\end{array}$ & 31 \\
\hline HVAC & 62 & 0.19 & .0 .37 & 0.22 & $\begin{array}{c}0.22 * \\
(0.06)\end{array}$ & $\begin{array}{r}-0.44 \\
(0.61)\end{array}$ & $\begin{array}{r}0.06 \\
(0.04)\end{array}$ & $\begin{array}{r}0.08 \\
(0.06)\end{array}$ & $\begin{array}{r}1.97 \\
(1.13)\end{array}$ & 50 \\
\hline 兽 process & 62 & 0.65 & 0.85 & 0.59 & $\begin{array}{l}0.29 * \\
(0.08)\end{array}$ & $\begin{array}{r}0.46 \\
(0.86)\end{array}$ & $\begin{array}{r}0.02 \\
(0.06)\end{array}$ & $\begin{array}{r}0.07 \\
(0.10)\end{array}$ & $\begin{array}{r}0.68 \\
(1.86)\end{array}$ & 22 \\
\hline ב. waste heat & 62 & 0.42 & 0.61 & 0.33 & $\begin{array}{l}0.20 * \\
(0.05)\end{array}$ & $\begin{array}{r}0.04 \\
(0.41)\end{array}$ & $\begin{array}{l}-0.11 * \\
(0.05)\end{array}$ & $\begin{array}{r}0.05 \\
(0.07)\end{array}$ & $\begin{array}{l}2.49 * \\
(1.14)\end{array}$ & 36 \\
\hline motors & 62 & 0.68 & 0.81 & 0.40 & $\begin{array}{l}0.17 * \\
(0.06)\end{array}$ & $\begin{array}{l}-0.90 \\
(0.98)\end{array}$ & $\begin{array}{r}0.02 \\
(0.05)\end{array}$ & $\begin{array}{r}0.03 \\
(0.07)\end{array}$ & $\begin{array}{r}0.57 \\
(1.23)\end{array}$ & 20 \\
\hline HVAC & 73 & 0.22 & 0.42 & 0.26 & $\begin{array}{l}0.24 * \\
(0.06)\end{array}$ & $\begin{array}{l}-0.46 \\
(0.51)\end{array}$ & $\begin{array}{r}0.01 \\
(0.04)\end{array}$ & $\begin{array}{l}0.12 * \\
(0.06)\end{array}$ & $\begin{array}{l}-0.17 \\
(1.24)\end{array}$ & 57 \\
\hline 竎 process & 73 & 0.64 & 0.82 & 0.50 & $\begin{array}{l}0.23 \\
(0.06)\end{array}$ & $\begin{array}{l}-1.10 \\
(0.63)\end{array}$ & $\begin{array}{l}-0.02 \\
(0.06)\end{array}$ & $\begin{array}{r}0.12 \\
(0.06)\end{array}$ & $\begin{array}{l}-1.88 \\
(2.28)\end{array}$ & 26 \\
\hline 产 waste heat & 73 & 0.78 & 0.90 & 0.56 & $\begin{array}{l}0.24 * \\
(0.08)\end{array}$ & $\begin{array}{r}0.83 \\
(1.46)\end{array}$ & $\begin{array}{l}-0.09 \\
(0.12)\end{array}$ & $\begin{array}{r}0.13 \\
(0.09)\end{array}$ & $\begin{array}{l}-2.44 \\
(4.76)\end{array}$ & 16 \\
\hline motors & 73 & 0.33 & 0.56 & 0.35 & $\begin{array}{l}0.24 \text { * } \\
(0.05)\end{array}$ & $\begin{array}{l}-0.44 \\
(0.51)\end{array}$ & $\begin{array}{r}0.00 \\
(0.04)\end{array}$ & $\begin{array}{l}0.15 * \\
(0.06)\end{array}$ & $\begin{array}{r}0.05 \\
(1.04)\end{array}$ & 49 \\
\hline \multicolumn{4}{|c|}{ precision weighted average } & & $\begin{array}{c}0.22 * \\
(0.01)\end{array}$ & $\begin{array}{r}0.10 \\
(0.11)\end{array}$ & $\begin{array}{r}0.005 \\
(0.011)\end{array}$ & $\begin{array}{c}0.053 * \\
(0.013)\end{array}$ & $\begin{array}{r}0.18 \\
(0.26)\end{array}$ & \\
\hline \multicolumn{2}{|c|}{ equal weight average } & & & & $\begin{array}{l}0.24 * \\
(0.02)\end{array}$ & $\begin{array}{r}0.08 \\
(0.18)\end{array}$ & $\begin{array}{l}-0.004 \\
(0.016)\end{array}$ & $\begin{array}{c}0.058 * \\
(0.018)\end{array}$ & $\begin{array}{r}0.62 \\
(0.51)\end{array}$ & \\
\hline $\begin{array}{l}\text { observed ve } \\
\text { (std dev) }\end{array}$ & & & & & & $\begin{array}{r}0.09 \\
(0.12)\end{array}$ & $\begin{array}{r}5.56 \\
(1.27)\end{array}$ & $\begin{array}{r}6.05 \\
(1.09)\end{array}$ & $\begin{array}{r}0.05 \\
(0.06)\end{array}$ & \\
\hline
\end{tabular}


Table 2: Adoption Model Estimates

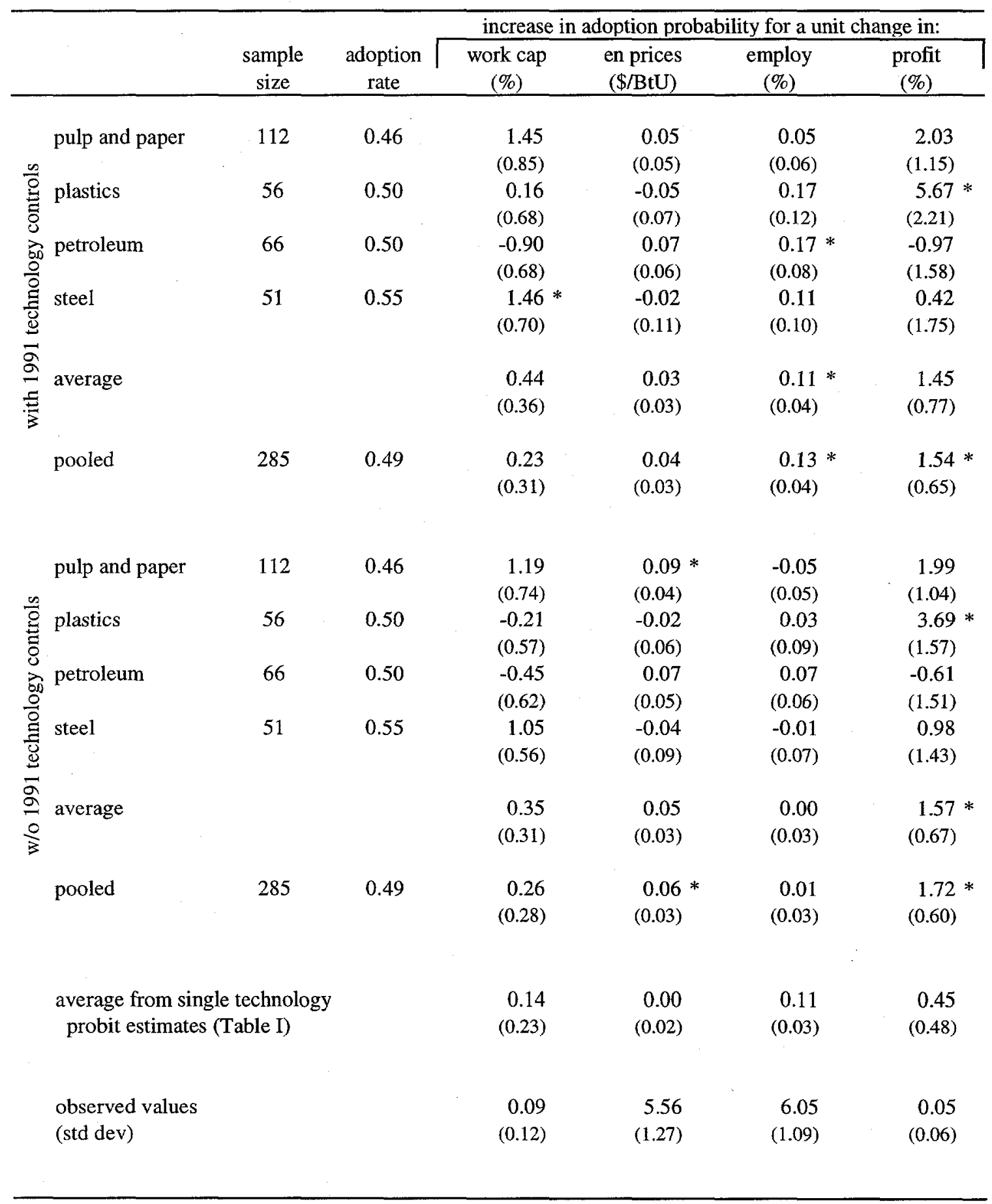




\section{A Data Appendix}

\section{A.I Databases}

The data used in this paper are drawn from several plant-level data sets and a firm-level developed by the U.S. Census Bureau:

- The Longitudinal Research Database (LRD). This is a pooled, cross-section, time series comprised of the establishment responses to the Annual Survey of Manufacture (ASM) and the quinquennial Census of Manufactures (CM) for over 50,000 establishments in each year. The LRD contains information on cost, outputs and inputs at the plant level. Detailed quantity and expenditure information for energy consumption are only available up to 1981 .

- The Manufacturing Energy Consumption Survey (MECS). Collected by the Department of Energy every three years beginning 1985, MECS contains detailed fuel consumption and expenditure data by establishment.

- Quarterly Financial Report (QFR). This data set, collected by the U.S. Census Bureau, includes income and retained earnings, balance sheets, and related financial and operating ratios for the domestic operations of all manufacturing corporations with assets over $\$ 250,000$, and corporations in the mining and trade areas with assets over $\$ 50$ million. These include almost 172,000 corporations with estimated assets of over $\$ 4.6$ trillion.

\section{A.2 Variable description}

Variables used in this study are constructed as follows:

\section{Adoption variables.}

We define two types of adoption variables on the left hand side of the model. The first one, for any specific general technology, is defined as 1 if no adoption in the year 91 but adopt the technology in year 94; defined as 0 if no adoption in both 91 and 94. The second type of adoption variable is defined as 1 if there is an adoption in any of the four technologies; defined as 0 if there is no adoption in any of the four technologies.

\section{Plant variables.}

- $\quad$ states energy prices: state energy prices of 91 ; 
Table 3: Descriptive Statistics for the variables used in the estimation

$\begin{array}{lrrr} & \begin{array}{c}\text { Number of } \\ \text { observations }\end{array} & \text { mean } & \begin{array}{r}\text { Standard } \\ \text { deviation }\end{array} \\ \text { Working capital (fraction of total assets) } & 316 & 0.085 & 0.116 \\ \text { State energy prices (dollars per million BTU) } & 316 & 5.563 & 1.265 \\ \begin{array}{l}\text { Employment logged) } \\ \text { ( After-tax profit (fraction of total revenue) }\end{array} & 316 & 6.050 & 1.085 \\ \text { computer HVAC } & 316 & 0.045 & 0.055 \\ \text { computer process cntrls } & 316 & 0.165 & \\ \text { waste-heat recycling } & 316 & 0.661 & \\ \text { variable-speed motors } & 316 & 0.579 & \\ \text { pulp and paper } & 316 & 0.589 & \\ \text { Petroleum } & 316 & 0.399 & \\ \text { Steel } & 316 & 0.231 & \end{array}$

- log employment: logarithm of total employment of year 91 .

Firm variables. These variables are five quarter average between the second quarter of 90 and 91 . For those observations with some quarter data missing, we use whatever number of quarters available to average.

- working capital: financial capital, defined as excess of current assets over total current liabilities, subtracts short-term debt including installments on long term debt and scaled by total assets;

- after-tax profit: Income (or loss) from operations/net sales.

Industrial dummy variables. The 4-digit industries studied are pulp and paper (SIC 2621), plastic (SIC 2821), petroleum refining (SIC 2911) and steel (SIC 3312). Using the steel industry as a reference, we created dummy variables for the other three industries. 


\section{A.3 Technology description}

Computerized climate controls allow the plant to reduce its energy bill by more efficiently control of heating, ventilation and air conditioning systems. Computerized process controls, in contrast, lead to indirect energy-savings by improving quality and reducing waste. In the plastics industry, for example, computers are used to quickly recognize and remedy aberrations in the cooling conditions surrounding the raw plastic, reducing the amount of plastic that must be scrapped.

Waste heat recovery reduces energy use by using otherwise wasted heat to replace raw energy use. In oil refining, for example, distilled oil is piped past incoming crude oil in order to preheat it, reducing the heat required for distillation. In steel, heat exchangers on smoke stacks are similarly used to channel steam back into the smelting process. Adjustable speed motors offer direct energy savings by eliminating the excess power provided by fixed-speed motors as needs fluctuate during production. Without this technology, this excess power is dissipated through friction or diverted to empty applications. 


\section{References}

Boyd, G. and S. Karlson (1993). "The Impact of Energy Prices on Technology Choice in the US Steel Industry.” Energy Journal 14(2): 47-56.

Calomiris, C. W. and R. G. Hubbard (1990). "Firm Heterogeneity, Internal Finance and 'Credit Rationing'." Economic Journal 100: 90-104.

Carpenter, R. E., S. M. Fazzari, et al. (1994). "Inventory Investment, Internal-Finance Fluctuations, and the Business Cycle." Brookings Papers on Economic Activity 2: 75-138.

Cohen, W. and R. Levin (1989). Empirical Studies of Innovation and Market Structure. Handbook of Industrial Organization. 2: Chapter 18.

Cummins, J. G., K. A. Hassett, et al. (1994). "A Reconsideration of Investment Behavior Using Tax Reforms as Natural Experiments." Brookings Papers on Economic Activity 2: 1-74.

David, P. A. (1966). The Mechanization of Reaping in the Ante-Bellum Midwest. Industrialization in Two Systems. H. Rosovsky. Cambridge, MA, Harvard University Press: 3-39.

Davies, S. W. (1979). "Inter-firm Diffusion of Process Innovation." European Economic Review 12: 299-317.

DeCanio, S. J. and W. E. Watkins (1998). "Investment in Energy Efficiency: Do the Characteristics of Firms Matter?" Review of Economics and Statistics: 95-107.

DOE/EIA (1998). State Energy Price and Expenditure Report 1995. Washington, DOE/EIA, 0376(95).

Downing, P. B. and L. J. White (1986). "Innovation in Pollution Control." Journal of Environmental Economics and Management 13: 18-27.

Fazzari, S. M., R. G. Hubbard, et al. (1988). "Financing Constraints and Corporate Investment." Brookings Papers on Economic Activity: 141-206.

Gelman, A., J. B. Carlin, et al. (1995). Bayesian Data Analysis. New York, Chapman \& Hall.

Griliches, Z. (1957). "Hybrid Corn: An Exploration in the Economics of Technological Change." Econometrica 25: 501-522.

Jaffe, A. B. and R. N. Stavins (1994). "The Energy Paradox and the Diffusion of Conservation Technology." Resource and Energy Economics 16: 91-122. 
Jung, C., K. Krutilla, et al. (1996). "Incentives for Advanced Pollution Abatement Technology at the Industry Level: An Evaluation of Policy Alternatives." Journal of Environmental Economics and Management 30(1): 95-111.

Levin, S. G., S. L. Levin, et al. (1987). "A Dynamic Analysis of the Adoption of a New Technology: The Case of Optical Scanners." Review of Economics and Statistics 69: $12-17$.

Long, W. F. and D. J. Ravenscraft (1993). The Quarterly Financial Report Database.

Malueg, D. A. (1989). "Emission Credit Trading and the Incentive to Adopt New Pollution Abatement Technology." Journal of Environmental Economics and Management 16: 52-57.

Mansfield, E. (1968). Industrial Research and Technological Innovation. New York, W.W. Norton.

Milliman, S. R. and R. Prince (1989). "Firm Incentives to Promote Technological Change in Pollution Control." Journal of Environmental Economics and Management 17: 247-265.

Oster, S. (1982). "The Diffusion of Innovation Among Steel Firms: The Basic Oxygen Furnace." The Bell Journal of Economics 13: 45-56.

Stole, L. A. and J. Zwiebel (1996). "Organizational Design and Technology Choice Under Intrafirm Bargaining." American Economic Review 86: 195-222.

Thirtle, C. G. and V. W. Ruttan (1987). The Role of Demand and Supply in the Generation and Diffusion of Technological Change. New York, Harwood Academic Publications. 